Correspondencia : Alicia Viviana Méndez ${ }^{1}$ Jean Carlos Centenaro Moraes ${ }^{1}$

Paulo Matheus Calisto da Silva $^{1}$

Alejandro Ernesto Vera Licea $^{2}$

${ }^{1}$ Alumnos de la Carrera de Medicina UNITEPC.

Medico supervisor del estudio por la Cátedra de Embriología y Genética en la UNITEPC y responsable del caso clínico en el

Hospital Príncipe de Paz de Puerto Quijarro,

Provincia German Busch, Bolivia.

med.2015unitepc@gmail. com

Procedencia y arbitraje: no comisionado, sometido a arbitraje externo

Recibido para publicación: 09 de enero de 2017

Aceptado para publicación: 27 de febrero de 2017

Citar como:

Re Ci Sa UNI

2017; 2(1):32-43

\section{DEFICIENCIA DE ÁCIDO FÓLICO COMO POSIBLE CAUSA PRINCIPAL DE ANENCEFALIA Y MALFORMACIONES MÚL- TIPLES EN UN CASO ESPECIFICO.}

\author{
DEFICIENCY OF FOLLIC ACID AS A POSSIBLE CAUSE OF \\ ANENCEPHALIA AND MULTIPLE MALFORMATIONS IN A \\ SPECIFIC CASE.
}
DEFICIÊNCIA DO ÁCIDO FÓLICO COMO POSSÍVEL CAUSA DE ANENCEFALIA E MALFORMAÇÕES MÚLTIPLAS EM UM CASO ESPECÍFICO.

\section{RESUMEN.}

La deficiencia de ácido fólico es la causa más frecuente entre todos los causantes multifactoriales de defectos congénitos, defectos del tubo neural, labio leporino/paladar hendido, malformaciones cardíacas y atresias esofágicas, malformaciones orofaciales, por mencionar las más importantes.

En el caso estudiado se evidencia la deficiencia de ácido fólico en el resultado gestacional de una paciente joven de 27 años de edad, que, en control prenatal, tardíamente se diagnostica en el feto anencefalia, malformaciones múltiples a nivel craneal con complicaciones cardíacas y esofágicas incompatibles con la vida. En orientación genética, la paciente, con apoyo familiar y ante los resultados de estudios médicos, decide por la interrupción de la gestación, lo que confirmara después del adelanto terapéutico del parto, los hallazgos visualizados por imagenología.

La importancia del estudio de este caso, radica en los indicios observados a nivel nutricional que lleva a esta deficiencia y que evidencian que, posiblemente, sea la causa principal del fenómeno produciendo estos defectos congénitos en el fruto de la fecundación. El hecho envuelve cuestiones de bioética y el fenómeno podría ser evitado, desde políticas de salud pública más puntuales en este tema, por medio de campañas de concientización, especialmente en mujeres jóvenes, con información nutricional especifica o con el simple suministro de ácido fólico como suplemento vitamínico antes y al inicio del embarazo.

Palabras clave. Deficiencia de ácido fólico, anencefalia, malformaciones múltiples. 


\section{ABSTRACT.}

Folic acid deficiency is the most common cause among all multifactorial causes of congenital defects, neural tube defects, cleft lip / palate, cardiac malformations and esophageal atresias, orofacial malformations, to mention the most important ones. In the case studied, there is evidence of folic acid deficiency in the gestational outcome of a 27-year-old female patient who, in prenatal control, is late diagnosed in fetal anencephaly, multiple malformations at the cranial level with incompatible cardiac and esophageal complications. with the life. In genetic counseling, the patient, with family support and before the results of medical studies, decided on the interruption of pregnancy, which confirmed after the therapeutic advance of delivery, the findings visualized by imaging. The importance of the study of this case, lies in the indications observed at the nutritional level that leads to this deficiency and that show that, possibly, it is the main cause of the phenomenon producing these congenital defects in the fruit of fertilization. The fact involves issues of bioethics and the phenomenon could be avoided, from more punctual public health policies in this topic, through awareness campaigns, especially in young women, with specific nutritional information or with the simple supply of folic acid as a supplement vitamin before and at the beginning of pregnancy.

KEYWORD. Folic acid deficiency, anencephaly, multiple malformations.

\section{RESUMO.}

A deficiência de ácido fólico é a causa mais comum para todos os defeitos de nascimento de causa multifatorial, defeitos do tubo neural, fissura lábio/palato, malformações cardíacas e atresia de esôfago, malformações orofaciais, para mencionar os mais importantes.

No caso estudado, se evidencia a deficiencia de ácido fólico no resultado gestacional de uma paciente jovem de 27 anos de idade, que, no pré-natal, tardiamente se diagnostica no feto anencefalia, malformações múltiples a nível cranial com complicações cardíacas e esôfago incompatível com a vida. No aconselhamento genético, a paciente com apoio famíliar e com os resultados dos estudos médicos, decide sobre a interrupção da gravidez, que confirmará após a entrega do avanço terapêutico, visualizado por achados de imagem.

A importância do estudo deste caso reside na evidência observada nutricionalmente llevando a essa deficiência e mostrar que, possivelmente, a principal causa do fenômeno produzindo estes defeitos congénitos no fruto da fecundação. $O$ fato envolve questões bioéticas e o fenômeno poderia ser evitado, desde politicas de saúde pública más pontuais neste tema, através de campanhas de sensibilização, especialmente em mulheres jovens, com informação nutricional específico ou simples fornecimento de suplementação de vitaminas antes e no início da gravidez.

Palavras chave. Deficiência de ácido fólico, anencefalia, múltiplas malformações 


\section{INTRODUCCIÓN.}

A pesar de que muchas patologías congénitas no muestran ningún patrón de herencia mendeliano reconocido, la medicina sabe que pueden deberse a multifactoriales causas genéticas como también así, a causas ambientales. Este herencia multifactorial también puede deberse a mutaciones en un gen especifico o de varios pero en general no se trata de trastornos monogénicos y si más bien son resultantes de una interacción compleja de varios factores de predisposición que desencadena, acelera o incrementa los defectos congénitos por falla en algún proceso del desarrollo celular embrionario afectado directamente en esta interacción.

El ser humano depende desustancias exógenas para el crecimiento, desarrollo y mantenimiento de la vida, haciéndose necesarios fuentes de carbono, nitrógeno, azufre, elementos inorgánicos y orgánicos que incluyen complejos ácidos grasos, aminoácidos esenciales y las vitaminas, que al no poder ser sintetizados por el cuerpo, precisan ser adquiridas por medio de la dieta.

Con los conocimientos en creciente producción en la comunidad científica, desde el descubrimiento del genoma humano, se reconoce la relación estrecha entre genes y nutrientes como causa de defectos congénitos ${ }^{1}$. Actualmente, vemos crecer el campo de la nutrigenómica, con los aportes de esta ciencia en los cambios de hábitos y estilos de vida de las personas visando la prevención de enfermedades. Las vitaminas son nutrientes con acción reguladora, siendo definidas por Casimiro Funk, en el año 1912, con las siguientes características: no pueden ser sintetizadas en cantidades suficientes y deben ser aportadas por la dieta, las mismas se encuentran en cantidades muy pequeñas en los alimentos, cuando están ausentes en la dieta o su absorción es deficiente, se produce una determinada enfermedad carencial. El ácido fólico tiene como sustancia bioquímicamente activa al ácido folinico ${ }^{2}$. También se lo conoce bajo el nombre de folatos, folacina o Vitamina B9 ya que pertenece al Complejo B, su etimología se remite a latínfolium (hoja), porque la primera vez que se lo aisló fue en hojas verdes de verduras. Como sustancia, se la describe como amarillenta, cristalina y pertenece al grupo de compuestos Pterinos (folatos, folacina, pteroilmonoglutamato). Se presenta en 150 formas diferentes, la mayor parte en alimentos y en forma reducida, lábiles y de fácil oxidación. Se lo considera un nutriente esencial, el cuerpo humano no lo almacena, no lo sintetiza y por eso necesita de la ingestión diaria del mismo. La función principal de este grupo de compuestos es actuar como coenzima transportando carbono. Tiene una función importante en la síntesis de las purinas: guanina y adenina y de la pirimidina: timina, siendo estas utilizadas en la formación de nucleoproteínas: ADN y ARN, esenciales para el crecimiento, migración y multiplicación celular, imprescindibles para el cierre del tubo neural que depende de una división celular rápida y en la diminución de los niveles de homocisteína en sangre, factor de riesgo de enfermedades cardiovasculares y trastornos durante el embarazo que pueden contribuir al bajo peso del individuo al nacer y a la mortalidad infantil ${ }^{3}$. El metabolismo del ácido fólico logra niveles adecuados de metilación del ADN necesario para el proceso de morfogénesis. La absorción se realiza principalmente en la porción proximal del intestino delgado, donde los folatos (poli glutamatos reducidos) 
son transformados en mono glutamatos para su absorción rápida. Las concentraciones normales de folato sérico son superiores a $9 \mathrm{ng} / \mathrm{ml}$ en eritrocitos. Las reservas corporales de folatos son de $12-15 \mathrm{mg}$ y son suficientes para 2 a 4 meses antes que se inicien los síntomas de la deficiencia en caso de falta de esta vitamina. Existen varias fuentes para la adquisición diaria: productos animales, como carne, hígado, huevo, leche, productos vegetales de hojas verdes, lentejas, garbanzos, naranjas, cereales integrales, semillas de sésamo, girasol, maní, etc. En algunos países se fortifican las harinas de trigo con hierro y ácido fólico, siendo así el consumo de pan el responsable por el $25 \%$ de los requerimientos diarios de esta vitamina ${ }^{3}$. El cuerpo absorbe el $50 \%$ del folato contenido en la alimentación mientras que puede absorber el $85 \%$ en los alimentos enriquecidos y el $100 \%$ de los suplementos vitamínicos ${ }^{4}$. Se puede perder del $50 \%$ al $95 \%$ de los folatos en el proceso de cocción, preparación y durante el almacenamiento de los vegetales a temperatura ambiente.

Algunos fármacos tales como los antinflamatorios no esteroides, metrotrexate, aspirina, aminopterin y sustancias como el etanol y el cigarro inhiben la $E$ folato conjugasa y producen deficiencias de las vitaminas. Epilépticas medicadas con carbamazepina, valproato de sodio magnesio o fenitoina, o las mujeres que ingieren anticoncepcionales por tiempo prolongado antes del embarazo y las diabéticas, pueden presentar déficit de ácido fólico por los efectos teratogénicos de estos medicamentos. Los riesgos de defectos del tubo neural se elevan en estas condiciones. Existe en la literatura médica numerosos estudios que demuestran que la forma sintética del ácido fólico previene los defectos del tubo neural y otras malformaciones.

Existen varios factores que pueden alterar el metabolismo de esta vitamina. Los medicamentos, como anteriormente se ha mencionado, al igual que otras drogas, como las anti convulsionantes que inhiben la enzima dihidrofolatoreductasa, los anticonceptivos orales, el alcohol, cimetidina, cotrimoxazol, fluoruracilo, isoniacida, litio, etc. También el déficit puede sobrevenir después de una cirugía gástrica, o por síndrome de mala absorción intestinal, desnutrición o simplemente por la no ingestión de sus principales fuentes alimenticias, o sea, por causa de una dieta insuficiente. También pueden intervenir factores genéticos como mutaciones en alguna de las enzimas que participan en el metabolismo del ácido fólico. Una de las causas más comunes para la deficiencia del ácido fólico, es la mala nutrición, interfiriendo así en la síntesis del DNA, RNA y metabolismo de algunos aminoácidos ${ }^{13}$. Se ha asociado con la aparición de labio leporino y paladar hendido, malformaciones del tracto urinario como la extrofia de vejiga, de las extremidades, de defectos de pared abdominal como la gastrosquisis u onfalocele. También existe en la comunidad científica la hipótesis que un metabolismo anormal del ácido fólico podría elevar el riesgo de trisomía 21, pues esta vitamina es necesaria para la metilación del ADN. La deficiencia de ácido fólico también aparece frecuentemente en la literatura como causa de depresión. Los defectos del tubo neural (DTN) se relacionan directamente con este déficit. Son malformaciones muy graves del sistema nervioso central (anencefalia, espina bífida, encefalocele). $Y$ son responsables de mortalidad neonatal y pos neonatal y de morbilidad en los niños que sobreviven. Su frecuencia parece variar con los factores sociales que intervienen ambientalmente. El tubo neural es una estructura embrionaria que debe 
cerrarse entre la tercera y la cuarta semana de gestación y por lo tanto la prevención de este tipo de defectos debe realizarse en forma pre-concepcional. Los progenitores de niños con defectos del tubo neural tienen un riesgo incrementado de recurrencia en futuras generaciones ${ }^{15}$.

La anencefalia es una malformación del encéfalo ${ }^{5}$, originada de una neurulación anormal a mediados de la 4 y 5 semana gestacional. Es la forma letal más común del sistema nervioso central, donde el feto anencefalo a término, puede nacer muerto o vivir por algunas horas o días ${ }^{6,7}$. En Brasil la incidencia es de cerca de 18 casos para cada 10.000 nacidos vivos ${ }^{8}$. Desde 1992 jueces y promotores públicos autorizaron cerca de 3000 casos de interrupción del embarazo de fetos anencefalos en Brasil.

Se afirma que el desarrollo normal es dependiente de dos fenómenos principales: instrucciones genéticas para la morfogénesis y la capacidad de los tejidos para completar el proceso metabólico general, lo que requiere que las células sobrevivan y se repliquen. El desarrollo normal y anormal ocurre de manera que los órganos y sistemas son formados y estabilizados hasta la diferenciación final tornarse completa, dependiente de instrucciones genéticas hasta un plano celular mas habilitado en la formación de los tejidos para conducir las funciones metabólicas generales esenciales para la sobrevivencia de la célula. La anencefalia en humanos, en el encéfalo posterior, aparece como una masa vasculo esponjosa (estroma angiomatoso) en la base del cráneo, con ausencia simétrica de la calvaría encima de las orbitas ${ }^{9}$. Cuando el defecto del cierre del tubo neural es extenso, puede estar asociado a raquitismo ${ }^{10}$. Estando los hemisferios cerebrales ausentes, dando una apariencia hundida a la cabeza, el diencéfalo y el mesencéfalo pueden estar ausentes también, y la hipófisis, en la mayoría de las veces está presente, aunque sea de forma muy pequeña, siendo que la causa inmediata de la anencefalia se trata especialmente de la falencia en el crecimiento del telencéfalo. Otra característica marcante es el aumento desproporcional de la región de los hombros ${ }^{11}$. A pesar de esta anomalía ser llamada de anencefalia (ausencia de encéfalo) siempre está presente tejido neural funcionante, también denominándose meroanencefalia (ausencia de parte del encéfalo) ${ }^{9}$. Se sospecha de meroencefalia in útero cuando es detectado un nivel elevado de alfa-feto-proteína en el fluido amniótico. Este, cuando no se encuentra en exceso, posiblemente por faltar al feto el control nervioso necesario para la deglucióndel fluido amniótico, no yendo para el intestino para su absorcióny siendo subsecuentemente transferido para la placenta a fin de ser eliminado9, 7 . La arquitectura general del cerebro es alterada, siendo los hemisferios desarrollados por debajo del área de invaginación telencefálica y bordes del conducto diencefálico que los recubren, o sea, el tejido nervioso no es recubierto por ninguna formaciónósea ni cutánea (ectodermo) ${ }^{12}$. En niñas las malformaciones del sistema nerviosos son más frecuentes que las digestivas y cardíacas al contrario de lo que ocurre en el sexo masculino ${ }^{10}$. Los caucásicos son mas afectados que los de raza negra. Son mas frecuentes cuando las concepciones se dan en otoño (hemisferio norte) o primavera (hemisferio sur), las causas de este fenómeno todavía son desconocidas. En relación a la edad materna existe mayor acometimiento en hijos de mujeres con más de 35 años y con nivel socio económico desfavorable. 
La prevención gira en torno al suministro del suplemento de ácido fólico en el periodo de la preconcepción y la concepción. La Organización Mundial de la Salud recomienda 0,4 miligramos por día de ácido fólico para la prevención de ocurrencias de defectos del tubo neural. La anencefalia puede ser diagnosticada en el período prenatal a través del dosaje de la alfa-feto-proteína en el suero materno, en el líquido amniótico, o por ecografía, como lo fue en este caso, aquí estudiado. La mayoría de los casos son diagnosticados por ecografía, donde una vez identificado el fenómeno, no hay margen de error. No existe cura para anencefalia, no habiendo perspectivas de tratamiento o sobrevivencia para un feto que llegue a nacer con esta anomalía ${ }^{25}$.

Entre otras malformaciones múltiples que pueden asociarse al cuadro anterior destacamos las malformaciones orofaciales, que constituyen defectos estructurales de la cara y de la boca donde se destacan por su frecuencia el labio leporino y el paladar hendido según se afecten el labio o el paladar respectivamente, estos pueden presentarse independientemente, pero en un $50 \%$ de los casos aparecen asociados. Las fisuras de labio y paladar son deformidades congénitas caracterizadas por la interrupción en la continuidad de los tejidos del labio superior, reborde alveolar superior y del paladar, de forma parcial para cada uno de estos elementos o de manera más abarcadora, cuando mas de uno o todos los segmentos del tercio medio del rostro se presentan comprometidos. Pueden ser unilaterales, bilaterales o medianos. El desarrollo inicial del rostro es dominado por la proliferación y migración del ectomesenquima involucrado en la formación de las cavidades nasales primitivas ${ }^{26}$. En torno del día 28 de vida intrauterina, espesamientos localizados se desarrollan en el ectodermo de la prominencia frontal en posición rostral a la abertura del esomodio. Tales espesamientos son placoides olfatorios. Una rápida proliferación de la mesénquima subyacente ocurre en torno de las saliencias de los placoides en la prominencia frontal anterior, produciendo también, una saliencia en forma de herradura que transforma el placoide olfatorio en una fosita nasal. El brazo lateral de cada herradura es llamado de proceso nasal lateral medial. Entre los dos procesos nasales, se encuentra una nueva área formada por una depresión denominada proceso frontonasal.

Los procesos nasales mediales de los dos lados, junto con el proceso frontonasal forman la porción media de la nariz, porción media del labio superior, porción anterior del maxilar y el paladar primario. Las causas de esa malformación congénita también abarca factores genéticos, drogas y medicamentos teratógenos, entre los más importantes ${ }^{27}$.Las fisuras labio palatinas están entre las anomalías más comunes, afecta a uno de cada 700-750 recién nacidos. Las zonas comprendidas por las fisuras bucales comunes son el labio superior, el reborde alveolar, el paladar duro y el paladar blando. Ligeramente mas del $50 \%$ son fisuras combinadas del labio y el paladar y aproximadamente la cuarta parte de ella es bilateral. Se ha comprobado que las fisuras del labio son más frecuentes en varones mientras que las fisuras aisladas del paladar son más comunes en las mujeres. ${ }^{28} \mathrm{El}$ compromiso del labiofisurado es más frecuente del lado izquierdo que del derecho, careciendo de explicación estos fenómenos y la causa subyacente de la deformidad se comprende solo de una manera parcial ${ }^{24}$.Así como en la anencefalia los medicamentos anti-convulsionantes y sedantes, la anticoncepción hormonal prolongada antes del embarazo, la diabetes gestacional, la edad materna 
mayor a 40 años y menor de 20 años, son posibles causales, además de la metrorragia en el primer trimestre, los trastornos emocionales, el alcoholismo materno, el habito de fumar y la deficiencia de ácido fólico anteriormente ya enunciada. ${ }^{29} \mathrm{~A}$ diferencia de la anencefalia, (si este fenómeno se da aisladamente de la anencefalia), el tratamiento para el labio leporino y paladar hendido es quirúrgico, soliendo cerrar el labio leporino entre los 3 y 6 meses de edad, pudiendo ser necesarias otras cirugías si persisten complicaciones nasales extensas. El paladar hendido generalmente cierra entre el primer y segundo año de vida con apoyo interdisciplinar, ortodoncistas y terapeutas del lenguaje. ${ }^{30} \mathrm{El}$ apoyo psicológico también es importante para el intercambio de experiencias y manejo del stress causado por la afección en pacientes y familiares.

\section{DESCRIPCIÓN DEL CASO CLÍNICO.}

El caso aquí presentado corresponde a una paciente de sexo femenino, joven de 27 años de edad, de raza mestiza, originaria de la chiquitana boliviana, embarazada aproximadamente en la semana 30 de gestación, que se presenta a control prenatal y carece de controles por imagen anteriores que acuse alguna alteración o anormalidad en el periodo prenatal. De nivel socio económico desfavorable, actualmente escolarizándose tardíamente en curso de educación para adultos, con apoyo familiar notorio a través de la presencia de la madre y familiares, lo que posibilita la discusión del caso con la paciente y su familia desde múltiples perspectivas. En este primer contacto de control prenatal se procede a la solicitación de exámenes de laboratorio de rutina y se realiza inmediatamente ecografía obstétrica, siendo inmediatamente diagnosticado, malformaciones complejas congénitas sin ningún margen de error, fácilmente detectadas por anormalidades y diferencias biométricas descriptas posteriormente.

\section{ANTECEDENTES DE IMPORTANCIA.}

La paciente relata un embarazo anterior con muerte inter útero del feto por causa de trabajo de parto demorado sin asistencia medica a tiempo y estrangulación fetal por cordón umbilical causando el deceso intrauterino del natimorto.

La paciente manifiesta en entrevista tres periodos de depresión profunda.

También relata el inicio gestacional marcado por fiebre intermitente sin origen esclarecido, baja inmunidad, cansancio y debilidad generalizada en los meses anteriores a la entrevista.

En la entrevista el testimonio de la paciente acusa una dieta desequilibrada.

\section{INTERROGATORIO.}

La paciente fue interrogada por el médico responsable del caso y el interrogatorio se basó más en la búsqueda de datos obligatorios de los procedimientos normales para la elaboración de historia clínica y la realización de exámenes complementarios a la 
rutina de control prenatal. Se anexan evidencias de estos datos en los formularios propios del sistema Hospitalario que en la entrevista oral pos quirúrgica se confirman y corrigen, como por ejemplo, el dato de un embarazo anterior con perdida fetal ausente en la historia clínica.

\section{EXPLORACIÓN FÍSICA.}

La paciente presenta contextura física delgada, cráneo normo encéfalo con buena implantación pilosa, de rostro simétrico, ojos y mucosas hidratadas y fosas nasales permeables. Su tórax es simétrico, con elasticidad y expansibilidad consistente. El abdomen en la inspección se presenta globoso a expensas del embarazo con una altura de $28 \mathrm{~cm}$, donde se detecta feto en posición transversa superior. De contextura musculo esquelética en tono normal eutrófico, sin ganglios, sin adenopatías visibles o palpables. A nivel genitourinario no se presentan quejas ni tampoco en el sistema motor. Sus reflejos son normales, a nivel vascular presento llenado vascular menor a 3 segundos y su estado de conciencia a nivel neurológico es normal, orientada en el tiempo y espacio como persona.

\section{ESTUDIOS DE APOYO DIAGNOSTICO Y RESULTADOS.}

Se realiza ecografía obstétrica obteniéndose los siguientes datos: Se realiza la medición de la longitud del fémur del feto se calcula la 30 semana de gestación compatible con el control personal de la paciente e historia clínica de la misma. Al buscar circunferencia abdominal no se visualiza estomago acusando una posible atresia esofágica. Las configuraciones del corazón son sospechosas de alguna malformación ya que no se localizan todas las estructuras normales. Al verificar cráneo se observa total ausencia de la calvaría craneal siendo ausente desde la altura de la línea ciliar, siendo ausente también el hueso frontal. No se encuentra cerebro desarrollado ni estructura de masa solida semejante. Malformaciones orofaciales a nivel de labios y paladar. Conclusión: Malformaciones múltiples de alta complejidad.

\section{DIAGNOSTICO.}

Se diagnostica en la gestación de aproximadamente 30 semanas, un feto con malformación compleja: acraneo, o sea sin el hueso craneal de la calvaría, diagnosticando anencefalia, atresia esofágica, probablemente cardiacas, entre otras malformaciones orofaciales.

\section{INTERCONSULTAS.}

El caso es discutido y analizado con otros médicos del hospital y con la dirección Hospitalar para poder interdisciplinariamente encaminar el caso e informar a la paciente y familiares el diagnostico resultante y las opciones de tratamiento terapéutico a seguir según la realidad detectada. 


\section{TRATAMIENTO.}

Se ofrece orientación genética con detalle informativo sobre las malformaciones detectadas según biometría fetal normal y las diferencias anormales detectadas que manifiestan incompatibilidad con la vida.Se procede a la discusión de la situación con la gestante y con los familiares que la acompañan.

Aclarando a la paciente y a la familia que no existe potencialidad de vida para el feto de acuerdo a la gravedad de las malformaciones diagnosticadas y que el análisis debe centrarse en la salud de la gestante, para la familia existe tres opciones decisionales según el dialogo que se establece:

1. Realizar la interrupción del embarazo, por cesárea, o sea, el adelanto terapéutico del parto, salvaguardando la salud de la gestante.

2. No realizar la interrupción del embarazo hasta que se manifieste la necesidad por sintomatología, poniendo en riesgo la vida de la gestante.

3. No realizar ningún procedimiento hasta que se produzca el parto que será de alto riesgo por la situación detectada, asumiendo la familia la responsabilidad de la salud de la gestante.

\section{RESULTADOS CLÍNICOS.}

El equipo investigador-observador también se manifiesta de forma escrita post solicitación del médico responsable del caso realizando consideraciones médicas y bioéticas implicadas en el caso. Los resultados clínicos de la anticipación terapéutica del parto del feto con malformaciones múltiples se evidencian en el estado físico y psico-social de la gestante en el momento del alta, con semblante recuperado y anímicamente recompuesta. En la entrevista se mostró con actitud comprensiva al proceso ocurrido y las recomendaciones finales se centraron en los cuidados postoperatorios y nutricionales para la recuperación de su persona. Las malformaciones múltiples fueron confirmadas en la observación clínica del feto lo que demostró la incompatibilidad con la vida, motivo por lo cual no resistió a la cesárea naciendo muerto. El estado nutricional de la paciente es relevante para su mejoramiento físico y se recomienda observar estrictamente el retorno médico para control sanguíneo, para evitar anemias y deficiencias vitamínicas.

\section{CONCLUSIONES}

Existen varios factores que pueden causar el aparecimiento de anencefalia (radiaciones, virus, determinadas drogas durante el periodo gestacional, contacto directo con productos tóxicos) pero en este caso especifico parece ser el mas probable el factor ambiental nutricional resultante por la no absorción o deficiencia, o ausencia del ácido fólico en el metabolismo de la madre gestante, el cual probablemente es ocasionado por la no absorción de este elemento por el organismo o hasta por el alto índice de 
desnutrición ya observado en algunos países subdesarrollados del cual Bolivia, estadísticamente, hace parte. El analfabetismo nutricional se mostró como factor de riesgo para el surgimiento de estos defectos congénitos, que potencializan la probabilidad de deficiencia de ácido fólico entre otras vitaminas. La información medic0-cientifica y la orientación genética con apertura al diálogo y la relación de respeto entre médico-paciente de cosmovisiones y convicciones religiosas o no religiosas como fuente segura para la toma de decisión autónoma del sujeto, en este caso la paciente y su familia, fueron de vital importancia para el desenlace de este caso, que opto por focar en la salud de la gestante como prioridad ya que el feto no presentaba potencialidad para la vida a partir de las conclusiones aportadas del análisis de las graves malformaciones diagnosticadas.

Las malformaciones múltiples detectadas acusaron incompatibilidad con la vidalo que fue corroborado en la observación clínica del feto natimorto que no presento potencialidad para la vida y de esta manera, paciente y familiares participaron de todo el proceso de manera consciente, responsable y participativa, siendo informados y esclarecidos en todo momento del proceso terapéutico.

\section{REFERENCIAS BIBLIOGRÁFICAS.}

1. Mendez García R. El valor del acido fólico en la prevención primaria de defectos congénitos y otras enfermedades del ser humano. Rev. Cubana de Genética Comunitaria. Centro Nacional de Genética Medica, Ciudad de la Habana. 2008, Vol. 2 \# pág. 6-10.

2. Lardoyet Ferrer R. Taobada Lugo N (et al), Fundamentos del acido fólico en la prevención primaria farmacológica de defectos congénitos. Rev.Cub de MGI. Vol2 \#1 Ciudad de la Habana, 2005. Pág. 1-10.

3. Gonzalez González A.I, García Caraballo M Ma, Acido fólico en atención Primaria de salud, Centro de Salud El Greco-Madrid, 2003 1-6 pág.

4. Herrera Padrón M, Acido fólico y embarazo, Consultas medicas, Periódico Granma, 2008.

5. Lopez AC, Tratado de Clínica Medica, V. 1, San Pablo, Roca, 2005, 308.

6. Ramirez Espitia JA, Benavides FG, Lacasana-Navarro M, Martínez JM, , García AM, Benach J, Mortalidad por defectos del tubo neural en México 1980-1997, Salud Publica, México, 2003, 45:335-64.

7. Urdaneta C, Eliexer R. Síndrome de anencefalia con mielomeningocele, importancia del diagnostico en etapa final. Centro México 1988; 34:61-3.

8. Anencefalia: opinión Brasil: Febrasgo. http://www.febrasgo.org.br/anencefalia2. $\mathrm{htm}$. 
9. Moore KL, Persaud TV, Shiota K. Atlas colorido de EmbriologíaClínica 2 ed. Rio de Janeiro: GuanabaraKoogan, 2002, 284.

10. Moore KL, Persaud TVN. EmbriologíaClínica 7 ed. San Pablo: Elsevier, 2004, 609.

11. Fitzgerald MJT. Embriología Humana, sao Paulo: Harper\&Row, Brasil, 1980, 197 .

12. Crossman AR, Neary D. Neuroanatomía 2 ed. Rio de Janeiro, GuanabaraKoogan, 2002, 189.

13. Beckman DA, Brent RL, Mechanisms of teratogénesis. Ann Rev. PharmacolToxicol 1984, 24:483-500.

14. Nitrini R, Bacheschi LA, Neurología que todo medico debe saber, 2 ed. San Pablo, Atheneu, 2033, p418.

15. Thompson, Genética de los trastornos con herencia compleja. 6 ed. 2011, p1-23

16. Brasil, Consejo Federal de Medicina. Resolución CFM 1949/2010. Disponible en : www.cfm.org.br

17. Joao Paulo II. Evangelium Vitae (Carta Encíclica 1995) Roma, Librería Vaticana, 1995, Disponible en www.vatican.va

18. CDF-congregación para la Doctrina de la Fe. Donum Vitae (Declaración, 2007), Roma, Librería Vaticana, 2007, Disponible en www.vatican.va

19. CDF-Congregacion para la Doctrina de la Fe. Declaración sobre el aborto provocado, 12-13: AASS 66 (1974), 738.Disponible en www.vatican.va

20. T ertuliano, Apologeticum, IX, 8. In: Migne JP PatrologiaeCursusCompletus. Pars Latina v.I. Paris; Garnier; 1879.

21. Singer P. Ética practica, 3ed. San Pablo, MartinsFontes, 2002.

22. Camosy CC. Peter Singer and Christian Ethics. Beyondpolarization. Londres, Cambridge, 2012.

23. Dos Anjos, MF, Anencefalia y Bioética: visitando argumentaciones, Revista Bioethicos, Centro Universitario San Camilo, 2012, 6(2): 154-160 pág.

24. Castro Martínez, L, Labio leporino con paladar hendido, presentación de un caso clínico, 2012, Revista Electrónica Portales Medicos.com 
25. Alberto MVL, Galdos ACR, Miglino MA, Santos JM. Anencefalia: causas de una malformación congénita. Universidad de San Pablo, USP, San Pablo, Brasil, 2009.

26. Vega Jiménez, J, Acido fólico. Su repercusión en la prevención de defectos congénitos y enfermedades del adulto, 2012, Revista Electrónica Portales Medicos. com

27. Raposo da Silva, N; da Silva Bernardes. VC, Fendas Labio Palatinas, CISPRE, Universidad Veiga de Almeida, Brasil, 2015.

28. AJ Copp. Neurulation in the cranial region-normal and abnormal. Anat 2005; 207:623-35.

29. Secretaria de Salud México. Acido Fólico y la prevención de defectos al nacimiento. Mexico D.F. 2010.

30. Sadler- Lagman.Embriología médica. 11ed. Barcelona España. 2010. Pp.73 - 74$294-297$ 